\title{
Correction to: Age validation and seasonal growth patterns of a subtropical marsh fish: the Gulf killifish, Fundulus grandis
}

\author{
Anthony R. Vastano • Kenneth W. Able • Olaf P. Jensen • Paola C. López-Duarte • \\ Charles W. Martin • Brian J. Roberts
}

Published online: 7 June 2018

(C) Springer Nature B.V. 2018

Correction to: Environ Biol Fish (2017) 100(10):1315-1327

https://oi.org/10.1007/s10641-017-0645-7

The doi for the dataset mentioned in the acknowledgements is incorrectly cited as https://doi.org/10.7266 /N7SF2T32. The correct doi for this dataset is https://doi.org/10.7266/N7NZ85M4. Data are publicly available through the Gulf of Mexico Research Initiative Information \& Data Cooperative (GRIIDC) at https://data.gulfresearchinitiative.org.

The online version of the original article can be found at https://doi.org/10.1007/s10641-017-0645-7

A. R. Vastano $(\bowtie) \cdot$ O. P. Jensen

Department of Marine and Coastal Sciences, Rutgers University, New Brunswick, NJ, USA

e-mail: AnthonyVastano@gmail.com

K. W. Able · P. C. López-Duarte

Rutgers University Marine Field Station, Rutgers University,

Tuckerton, NJ, USA

C. W. Martin

UF/IFAS Nature Coast Biological Station, University of Florida,

Cedar Key, FL, USA

B. J. Roberts

Louisiana Universities Marine Consortium, Chauvin, LA, USA 